Revista Iberoamericana, Vol. LXXIV, Núm. 225, Octubre-Diciembre 2008, 1149-1159

\title{
LA DICOTOMÍA ESTRUCTURADORA EN SALVADOR NOVO: AFEMINAMIENTO Y VIRILIDAD
}

\author{
POR \\ Humberto GuerRA \\ Instituto Tecnológico y de Estudios Superiores de Monterrey \\ Campus Ciudad de México
}

A lo largo de prácticamente todo el siglo xx, la vida mexicana estuvo marcada por el autoritarismo político que, de manera irremediable, imprimió una forma de relación social específica. En el plano social y cultural, el machismo fue la expresión de esta particular organización. En este contexto, las voces disidentes eran disfrazadas, aquietadas o descartadas; por ello, la manifestación abierta de las disidencias sexuales, en específico la práctica homosexual, sólo podían ostentarse degradadamente y como constatación irrefutable de lo conveniente que resultaba la heteronormatividad. Los efectos y productos sociales y culturales emanados de la Revolución de 1910 no sólo prolongan la tradición heteronormativa, sino que la enfatizan y la actualizan en el surgimiento tanto de la nueva sociedad mexicana como del hombre nuevo que la construirá.

Así, la Revolución institucionalizada impone un modelo hegemónico en el que el nacionalismo cultural y artístico florece (lo "nacional” como infinitamente mejor al cotejarlo con lo “extranjero”); lo "autóctono”, lo “indígena”, lo “campesino” es más puro, confiable y verdadero frente a lo "mestizo” y “urbano”. El "hombre nuevo” es heterosexual, es fuerte (física y anímicamente), es paternalista (que no paternal), tiene don de mando, ejerce con decisión la autoridad y se jacta de sus errores que devienen en virtudes celebrables.

En este ambiente se desarrolla el movimiento de Contemporáneos que con el paso del tiempo ha ganado importancia tanto literaria como social. Relevancia que se debe a su postura a contracorriente en el plano artístico, apostando por un arte y una literatura ligadas a las vanguardias y desinteresadas en la referencialidad mexicana más próxima, y demostrando, al mismo tiempo, una heterodoxia sexual que resultaba, por lo menos, novedosa en su manifestación.

Por esto, los Contemporáneos libraron una doble batalla: para ingresar al canon y por su condición homosexual. Entre ellos, la figura de Salvador Novo se distingue por haber deambulado indistinta y exitosamente tanto en la disidencia y la 
marginalidad, como en los cauces más institucionalizados dereconocimiento que tuvo el Estado mexicano posrevolucionario. El propio Novo se jactaba constantemente de esta condición, y de ella parte el ensayo biográfico de Carlos Monsiváis, cuyo título hace justicia a la misma: Lo marginal en el centro.

La publicación definitiva de su autobiografía, La estatua de sal, confirma esta doble condición de marginal y adscrito al sistema en posición de privilegio de forma tal que el asunto Novo se convierte en paradigma de inclusión y exclusión simultáneas e irreconciliables. ${ }^{1}$ En esta situación, la obra literaria se ve opacada por el personaje público, puesto que el espacio autobiográfico es, tal vez, el más amplio dentro de la literatura mexicana, pero manifestado de manera inversa. No es el corpus autoral el más conocido, sino el personaje público quien puede inducir la lectura de la autobiografía (Lejeune 23). De igual manera, la triple identidad que requiere el pacto autobiográfico entre autor, narrador y personaje principal no sólo se cumple en este caso; sino que el lector de esta autobiografía la actualiza desproblematizadamente (Lejeune 23-26). Desde este punto de vista, la autobiografía de Salvador Novo cumple su función genérica en el acto de lectura, en el narratario que posee un conocimiento de la figura pública de Novo y se acerca a su texto autorreferencial para crear un sentido de realidad que, a su vez, se conforma al recolectar rasgos de fidelidad en la experiencia recreada y leída que, en su conjunto, permiten proporcionar significación al texto en su totalidad (Lejeune 36-37; Bruss 6-8) y que además refrenda al personaje público más que a la persona privada o literaria. Este proceso no puede ser soslayado, ya que el lector de La estatua de sal actualiza el texto no sólo como elaboración subjetiva de una identidad particular, sino que activa otra dimensión genérica de este tipo de textos: la autobiografía evidencia un discurso cuyo origen y consecuencias sociales persiguen fines diferentes a los ficcionales. Es así que el lector ideal de la autobiografía de Novo está más interesado, al menos en primera instancia, en esas consecuencias sociales que en las dimensiones subjetivas y netamente ficcionales del texto (Pozuelo Yvancos 191-92; Villanueva, “Realidad y ficción” 20). Es decir, se busca dar orígenes y antecedentes a una experiencia vital homosexual en un México que se abría a importantes procesos de modernización, lo cual constituye un horizonte de expectativas que conlleva la aceptación de un pacto referencial

1 Si bien no existe información fidedigna sobre la fecha de composición de La estatua de sal, se sabe que la primera versión impresa del texto aparece a principios de la década de 1980 en la revista marginal Nuestro Cuerpo, órgano de difusión del Frente Homosexual de Acción Revolucionaria, dirigido por Juan Jacobo Hernández. Pero sólo se publicó un fragmento del texto y dicha revista sólo apareció en un par de ocasiones. Por lo tanto, se puede deducir que el texto circuló de manera clandestina en algunos ambientes mexicanos, aunque no se sabe si también de manera fragmentaria o en su versión completa. De cualquier manera, la versión íntegra es la editada por El Consejo Nacional para la Cultura y las Artes, en su colección “Memorias mexicanas”, en 1998. 
buscado en este tipo de textos (Lejeune 36; Villanueva, "El realismo intencional" 189-94; Bruss 15). De esta forma, se refuerza la imagen pública de Salvador Novo y se constata su doble condición simultánea de disidente y de hijo mimado del Estado posrevolucionario.

Si bien la figura pública de Salvador Novo se convirtió en apologista del sistema mexicano del siglo xx, al punto de avalar los más cuestionables actos y procederes estatales, sobre todo en las postrimerías de su vida, La estatua de sal permite apreciar que el Novo personal no comulgaba con la mayoría de los productos sociales y culturales emanados de ese mismo Estado. Una franca actitud de rechazo permea las páginas de la autobiografía, ya que enfila sus comentarios más mordaces, agudos e irónicos en contra de los hombres fuertes revolucionarios; en oposición abierta a los próceres culturales y sus seguidores los normalistas. Se observa también una reelaboración festiva de los nuevos íconos artísticos que son categorizados como la "exaltación del tepalcate" que renace como un "sarampión nacionalista" (105). Al mismo tiempo, el texto se queja de la desaparición del superado sistema porfirista, y lo añora porque permitía un dandismo y un elitismo que aparentemente han desaparecido del repertorio de posibilidades del comportamiento socialmente permitido.

En Epistemology of the Closet, Eve Kosofsky Sedgwick apunta la dificultad de abandonar el binarismo epistemológico al momento de comprender y categorizar experiencias que se desvían de la norma (2). En este sentido, el texto de Salvador Novo refrenda este postulado, pues sus páginas se impregnan de esa imposibilidad al momento de nombrar la experiencia homosexual, ya que no puede hacerlo de otra forma que no sea binariamente, inscribiendo la tradicional dicotomía masculinofemenino. El homosexual es, entonces, un no-hombre, una aspiración a lo femenino que busca ser sujetado por un hombre verdadero. Este último es objeto de deseo y repudio de manera simultánea.

¿Cómo se textualiza esta actitud? ¿Cómo se problematiza? La respuesta está en un proceso desmitificador que Novo anecdotiza desde un inicio: él tiene el don de develar lo oculto, de descubrir la verdadera naturaleza de las situaciones y de las personas. En variadas ocasiones, el lector corrobora este proceder, presente desde la narración de los primeros recuerdos, en los que el niño Salvador se dedica a develar la auténtica configuración de lo que observa. Como cuando afirma que, en ocasión de realizar visitas de cortesía, él se dirigía a examinar las sábanas de las camas y sin empacho declaraba públicamente su dictamen al respecto o cuando se daba a la tarea de pintar bigotes y lentes en las fotografías que adornaban la sala familiar (45-46, 61).

Desde un inicio, el personaje-narrador-autor se adjudica esta cualidad desmitificadora que se manifiesta implícitamente en todo el texto, en concordancia con la mayoría de las características que Howarth señala como propias de las 
autobiografías teatrales, en las que el yo es idéntico a sí mismo siempre, es impertinente, los eventos relatados son pretendidamente espontáneos, impera la acción sobre la reflexión, y una de las motivaciones autorales básicas es cautivar al lector haciéndole percibir el carácter extraordinario de quien se retrata en el texto (367-74).

Si La estatua de sal textualiza la dicotomía masculino-femenino, entonces los sucesos relatados tenderán a organizarse de tal forma que se encuadren dentro de esta dicotomía. Al no haber una categorización propia de la experiencia homosexual, se recurre prácticamente, sin reparo alguno, a la identificación con lo femenino, y denodadamente se rechazan todos los atributos socialmente consensuados como supuestamente exclusivos del género masculino y que aquí quedan, indefectiblemente, asociados al varón heterosexual.

La estatua de sal contiene todo el repertorio de gestos y actitudes que caracterizan al hombre "verdadero", pero por descarte. El autobiógrafo se dedica a desmentir este repertorio al adoptar el opuesto, el femenino. A veces en franco desafío, otras con grandes dosis de culpabilidad. En este esquema tradicional, el rasgo más abarcador es el que adjudica al hombre una destreza y fuerza físicas privilegiadas, que se manifiestan en el dominio de las actividades deportivas que el autobiógrafo no comparte, sea por imposición materna, sea por considerarse inapto para ellas o ya bien por una inexplicable vergüenza frente a la camaradería homoerótica que se da en estas actividades exclusivamente masculinas:

Algunos médicos me han dicho que estuve óseamente constituido para ser un atleta, y aun descomunal por mi estatura. Pero una invencible pereza y un pudor neurótico de mostrarme desnudo cancelaron la posibilidad de mi oportuno desarrollo muscular, y fueron inclinándome a la actitud encogida y a la postura lánguida y sin sostén ni gracia que me caracterizarían para siempre. A salvarme de la gimnasia contribuyó felizmente para mi pereza el hecho de que Moisés Sáenz resolviera premiar con atribuciones de líderes a los alumnos que obtuvieran en las clases calificaciones altas. Los líderes simplemente vigilaríamos, exentos de la obligación de participar en los sudorosos ejercicios físicos. (98)

En estas líneas se percibeel saber médico que a la vez posibilita y niega la apropiación del atributo físico propio de la masculinidad: el narrador es físicamente apto, y con creces, pero una afectación neurótica impide el desarrollo natural. Es la mente la que impide el desarrollo físico, "normal”, de un joven hombre víctima de una vaga afectación mental. Esta posición representaba el conocimiento de vanguardia a mediados del siglo xx, época en que se redacta la autobiografía, y que empieza a ubicar la homosexualidad en el plano mental y no ya en el físico. Además, esta exclusión no resulta definitiva; por el contrario, se la hace trabajar a su favor gracias 
a un atributo paradójicamente también mental: su desempeño académico no sólo lo "salva" de la actividad física, también lo premia convirtiéndolo en líder que vigila el desempeño físico de sus compañeros. ¿№ es acaso este episodio muy ilustrativo de esa doble condición de marginal y adscrito al sistema? Novo huye, se salva, deja de padecer los rigores de un modelo masculino que ve en la actividad física uno de sus bastiones más evidentes y bondadosos, pero en la exclusión él se reinstala diferenciadamente. ${ }^{2}$

No obstante, este procedimiento no siempre rinde los mismos resultados, puesto que en ocasiones el narrador ve con recelo, culpa e imposibilidad cómo otros se entregan a la actividad deportiva o al baile, para los cuales él estaba imposibilitado, y lo racionaliza, de nuevo médicamente, al asegurar que los doctores de la Preparatoria Nacional le habían diagnosticado pie plano $(64,73)$.

La otra textualización de la masculinidad hegemónica se refiere a la actividad castrense, que toma una importancia peculiar en el recuento retrospectivo, pues en la primera mitad del siglo xx la ubicuidad del hombre fuerte es muy patente en todos los órdenes de la vida mexicana. ${ }^{3} \mathrm{Al}$ respecto, habría que notar un tratamiento narrativo diferenciado, pues mientras que las "hordas" revolucionarias-expresamente las villistas- son consideradas como una banda de forajidos brutales y asquerosos, a los militares al servicio de la Revolución institucionalizada se les aplica el don desmitificador que Novo se jacta de poseer.

Por medio de su iniciador sexual, el entrenador de béisbol Pedro Alvarado, Novo toma conciencia de lo ampliamente difundida que estaba su heterodoxia sexual, la cual anteriormente concebía como exclusiva de su persona, y a su vez se da cuenta que los hombres verdaderos, refrendados por el uso de la fuerza y el arma, también pertenecían a la heterodoxia:

Ya para marcharme, aturdido aún por las revelaciones de Pedro, le pregunté si también aquel militar que estaba con él en la esquina -y entonces él colmó sádicamente mi asombro al expresar que sí, que ese militar también, y que ya iría yo comprobando cómo los militares, particularmente, se inclinaban por acostarse con los hombres.

2 El mismo procedimiento se pone a trabajar en otros aspectos de la existencia, como lo es la educación formal (Novo 32-39).

3 No es fortuito que, por ejemplo, el movimiento poético antagónico a Contemporáneos, el abiertamente homofóbico Estridentismo, estuviera apadrinado por un militar, mientras que el primero fue financiado por una opulenta mujer cuyo padre había gozado de fama y fortuna durante el Porfiriato. Si esta ejemplificación no resulta suficiente, se pueden consultar los recuentos de los escritores considerados en Protagonistas de la literatura mexicana de Emmanuel Carballo. En este tomo, sólo los autores contenidos en la sección "Los nuevos autores" no tienen como referencia a militares y demás personificaciones de los "hombres fuertes”, mientras que todos los demás, por muy diversas razones y caminos, recalan en la ubicuidad de este tipo social (477-668). 
Yo le había creído todo: lo de Evaristo, lo del otro muchacho; como cuando en Torreón me dijo que Jorge González se acostaba con los motoristas, pude creérselo, porque me constaba que Jorge quería hacerlo conmigo. Pero esto de los militares no era posible. Ciertamente, recordé que en mi infancia, de los bigotudos oficiales del porfirismo se decía que usaban corset para mantenerse tiesos y erectos, y que teñían de negro sus bigotes, y de carmín sus labios y sus mejillas. Pero aquel recuerdo sólo ahora surgía en mí, automáticamente invalidado en la liquidación absoluta de esa época acartonada de los corsets que ya nadie usaba, del carmín y del albayalde; en el nacimiento -tampoco sino hasta ese momento advertido concretamente por mí- de un nuevo tipo de militares en que se conjugaban los rasgos feroces del villista de sombrero de palma o tejano, con la indumentaria un poco más formal, pero siempre viril, de kaki y de kepí, del ejército de don Venustiano Carranza, todos ellos de un clan aparte de la sociedad, y por ende sin duda libres de sus decadencias. Lo más que aceptaba mi renuencia a admitir tan repentina generalización de mis inclinaciones, era que aquel preciso militar amigo de Pedro fuera como él lo aseguraba [...]. (89)

En igual medida se traslucen en la cita anterior tanto la estupefacción como la incredulidad, y también la recurrencia del tópico narrativo de toma de conciencia de que la condición homosexual no es tan exclusiva y en el mejor de los casos (como sucede en esta autobiografía) abre la posibilidad de integrarse a una comunidad con los beneficios que dicha adscripción conlleva. Pero, como habíamos indicado, el texto de Novo no es particularmente reflexivo; ni siquiera en el momento de la elaboración rememorativa puede su autor ver el alcance beneficioso de la escena. Es decir, no logra formular el hecho de que la homosexualidad se expresa más allá de las apariencias o de la detentación de los atributos externos y estereotipados de la masculinidad hegemónica. Tal vez sería pedir demasiado: el yo configurado en el texto estaría entonces en una situación de compromiso muy difícil de manejar, puesto que ha apostado exactamente a lo contrario, la feminización del cuerpo y las "actitudes" homosexuales.

Sin embargo, en una especie de revancha, el narradorimplícitamente desmienteel argumento de que la posesión de los atributos masculinos socialmente consensuados denotan la verdadera heterosexualidad. Este es un procedimiento que sorprende en su textualización porque denota dos cuestiones de suma importancia. Por un lado, deja en evidencia que la homosexualidad no requiere como condición insoslayable del afeminamiento, y, por otro, constituye la cancelación rotunda de que el "verdadero" homosexual, el afeminado, no puede obtener satisfacción y correspondencia más allá del plano sexual; es decir, en el terreno emocional. Ambas son las dos caras de un mismo fenómeno.

En primer lugar, todas las relaciones sexuales que resultan añoradas por la satisfacción que provocaron y por su trascendencia existencial suceden con individuos 
cabalmente viriles y que en la mayoría de los casos son, además, figuras social y paradigmáticamente difusoras de la heterosexualidad hegemónica. La primera penetración experimentada por Novo es con nada menos que el entrenador del equipo de béisbol de la escuela primaria, Pedro Alvarado, quien además pertenece a un equipo profesional de ese deporte. Más tarde, Novo establece un vínculo sexual muy fuerte con el chofer de su tío, y después se dedica denodadamente a involucrarse con los conductores de lo que él mismo designa como "la nueva raza" que maneja los entonces novedosos autobuses en una Ciudad de México que ingresaba, en la segunda década del siglo xx, en la época de la transportación colectiva y motorizada. De igual manera, otros compañeros sexuales, condiscípulos de estudios, son todos poseedores de cualquier característica menos del afeminamiento que Novo procuraba cultivar para sí mismo. Es más, el yo configurado en el texto se regocija al señalar las inclinaciones homosexuales de individuos que socialmente eran considerados exponentes ejemplares de la heteronormatividad no sólo por su apariencia y actitud masculinas, sino porque ejercían actividades investidas necesariamente de esa masculinidad como atributo condicional al ejercicio profesional. Así, desfilan por la rememoración noviana tanto simples policías como los jefes máximos de esta instancia de autoridad, choferes que dominan el volante como anteriormente dominaron el caballo, diputados, militares, toreros, deportistas profesionales. Como es apreciable, implícitamente, sin percatarse la voz narrativa de ello, se desmiente la falacia que ve una relación directa entre comportamiento masculino y heterosexualidad. En todos los casos narrados en La estatua de sal, salvo en uno que se comenta posteriormente, los compañeros sexuales del narrador, los depositarios de sus aspiraciones erótico-afectivas o bien los personajes que más recurren al recuerdo entran en esta clasificación que es, en realidad, un homenaje a esos atributos masculinos que a su vez ha repudiado en su persona.

Esta situación nos pone en el camino de otra dimensión de la experiencia homosexual configurada en el texto. Los personajes que se asemejan a Novo en su actitud y procedimientos afeminados son reiteradamente descartados del repertorio de posibilidades sexuales y sentimentales. Esto no es otra cosa que un mecanismo francamente homófobo que, si bien es comprensible en un personaje como Salvador Novo (debido a la época en que vivió y a las experiencias que rememora), sigue vigente, aunque con una efectividad cada vez menor. Esos otros personajes no son muy valorados y su textualización denota la necesaria evidenciación del destino frustrado o truncado del homosexual "confeso", del afeminado. Este es el caso de un actor, apellidado Tovar Ávalos, con quien Novo se involucra muy tempranamente durante su proceso de inclusión en el ambiente homosexual de la Ciudad de México, y a quien conoce casi a la par que al pianista Ricardo Alessio Robles, proveniente de una encumbrada familia revolucionaria. En ambos casos, se trata de personajes que han renunciado a los atributos externos 
de la masculinidad, lo cual los emparenta con el joven Salvador. Sin embargo, las actitudes y destinos retratados en la autobiografía son elocuentes de una condición que parece insuperable para este tipo social: sus destinos son por lo menos triste constatación de que el ejercicio homosexual, en la versión abierta y afeminada, no puede llevarlos a buen puerto. El pianista (“Clarita para las amigas”), después de haber afincado sus expectativas amorosas en hombres heterosexuales que las más de las veces ni se enteraban de sus intenciones, tiene la ocurrencia de enamorarse de otro afeminado:

Cada vez más hundida en el hábito incontrolado de la cocaína, Clara empezó a perder la razón. Y una de sus chifladuras consistió en enamorarse de una loca-ella, que pretendía siempre la superstición de que uno se salaba si se acostaba con otra loca. Carlos Luquín, Elena Luca, como la propia Clara lo había bautizado, fue el repentino objeto de su solicitud, el apoyo y la autoridad que Clara anhelaba. A sabiendas de que Luquín andaría frotando su osamenta en los baños, con los clientes de los famosos de San Agustín (masaje completo. Había que pedir a Chon al vapor individual); o visitando a Chucha Cojines, Clara lo aguardaba toda la noche, asomada al balcón de su nuevo y lóbrego apartamiento frente a la Plaza Río de Janeiro; golpeteando la cajita hasta que se acababa la provisión de "nieve”, y amanecía y entonces iba a inyectarse sedol para derrumbarse en la cama -de que un día sus poderosos parientes rescataron, para sepultarlo casi en secreto, su cadáver escuálido, consumido en vida. (118)

Mejor caracterización no tiene el maestro Tovar Ávalos, quien al sentirse abandonado por Novo, ahora bajo la tutela y consejos del pianista Alessio Robles, lo denuncia con uno de sus tíos. Finalmente, el joven sale bien librado de la situación, y Tovar Ávalos desaparece del espectro temporal y geográfico de Novo, ya que se indica prolépticamente que emigrará para probar suerte en el naciente cine de Hollywood. No obstante, la huella que este personaje imprime en el texto está conformada por la precariedad económica, la ambigüedad física que le resulta repugnante al narrador y, sobre todo y de manera determinante, por la traición.

De esta forma, se puede apreciar que en la valoración de los personajes afeminados la autobiografía nos propone implícitamente un saldo negativo: la satisfacción erótica y emotiva entre personajes similares es imposible, la muerte es una solución penosa a esta permanente insatisfacción emocional. El afeminado es el peor enemigo de otro afeminado, de él no se puede esperar otra cosa que la delación.

A estas alturas, La estatua de sal parece un inventario de todos los estereotipos tradicionalmente adjudicados a la personalidad y la experiencia homosexuales en el que sólo faltaría la misoginia. El texto no la descarta, pues cuando es necesario criticar a algún personaje femenino se le adjudican características masculinas 
como degradantes. De esta manera, la versión femenina de los revolucionarios es "el tipo de esa marimacha revolucionaria que la 'Adelita' ha tratado de ennoblecer al teatralizarla” (55). Una visita que pernoctará en la casa familiar era "activa, hombruna señora con pince-nez" (79) y una aspirante a actriz presenta una imagen "hombruna, prognata y adusta" (86). En los tres casos citados se trata de mujeres que no encajan en los estereotipos de pasividad y feminidad propios de la época y, por lo tanto, son negativamente adjetivadas como masculinizadas. Este proceso de desvalorización es aplicable en ambos sentidos: el rechazo de las características convencionales de la feminidad y de la masculinidad ponen en falta condenable a quien proceda de esta manera, incluido autorreferencialmente el mismo autor.

La estatua de sal como registro de una mentalidad colectiva enfocada en los fenómenos de la experiencia homosexual resulta, entonces, una buena oportunidad para analizar los estereotipos adjudicados a la personalidad y experiencia homosexuales: desde la adopción del afeminamiento como manifestación de la diferencia (considerada necesariamente degradante) hasta la homofobia y la misoginia, las cuales contribuyen de manera determinante a la configuración de destinos siempre insatisfactorios.

\section{BiBLIOGRAFÍA}

Acero, Rosa María. Novo ante Novo: un novísimo personaje homosexual. Tesis doctoral. Santa Barbara: University of California, Santa Barbara, 1998.

Balderston, Daniel. "Poetry, Revolution, Homophobia: Polemics from the Mexican Revolution”. Hispanisms and Homosexualities. Sylvia Molloy y Robert McKee Irwin, eds. Durham: Duke UP, 1998. 57-75.

Bruss, Elisabeth W. Autobiographical Acts. The Changing Situation of a Literary Genre. Baltimore: John Hopkins UP, 1976.

Carballo, Emmanuel. “Salvador Novo (1904-1974)”. Protagonistas de la literatura mexicana. México, DF: Alfaguara, 2005. 315-53.

García Monsiváis, Margarita. "Salvador Novo: el ensayo, la risa, la duda”. El ensayo mexicano en el siglo XX. Reyes, Novo, Paz. Desarrollo, direcciones y formas. México: UAM-I (Texto y contexto, 24): 89-116.

"La prosa ensayística de Salvador Novo: características del estilo (humor, ironía) y estructuración del género”. AldeAm 14 (26-27 de julio de 1996): 155-63.

González Mateos, Adriana. "Patologías y contagios literarios”. Poligrafías IV. México, DF: UNAM, 2003. 167-77.

González Rodríguez, Sergio. "Salvador Novo: el narrador y el confidente". Los contemporáneos en el laberinto de la crítica. Rafael Olea Franco y Anthony Stanton, eds. México, DF: COLMEX, (Cátedra Jaime Torres Bodet, II), 1994. $377-84$. 
“El secreto y el estudio. Amores del joven Novo”. Nexos XIV/165(septiembre 1991): 9-15.

Guerra, Humberto. "La formación intelectual de Salvador Novo en La estatua de sal”. Fuentes Humanísticas 13/24 (2002): 25-39.

"Ironía como método prosopopéyico en La estatua de sal". Fuentes Humanísticas 12/23 (2001): 39-58.

Howarth, William L. "Some Principles of Autobiography”. NLH V/2 (invierno 1974): 363-81.

Lejuene, Philippe. Le pacte autobiographique. París: Éditions du Seuil, 1975.

Long, Mary Kendall. Salvador Novo: 1920-1940. Between the Avant-Garde and the Nation. Tesis doctoral. Princeton: Princeton University, 1995.

“Salvador Novo y la fragmentación del yo”. BdeM 22 (julio-agosto 1994): 36-40.

Marquet, Antonio. “Las chicas de Donceles”. Crónica dominical, suplemento de La Crónica (6 de diciembre de 1998): 10-11.

Monsiváis, Carlos. "Novo, poeta: las diversiones y las expiaciones”. BdeM 22 (julio- agosto 1994): 30-34.

"Salvador Novo. Los que tenemos unas manos que no nos pertenecen". Amor perdido. México, DF: SEP- ERA, (Lecturas mexicanas, segunda serie, 44), 1986. 265-96.

"El mundo soslayado (donde se mezclan la confesión y la proclama)". Salvador Novo, La estatua de sal. México: CONACULTA, 1998. 11-41.

“'Los que tenemos unas manos que no nos pertenecen' (A propósito de lo ‘Queer' y lo ‘Rarito')”. Debate feminista 8/16 (octubre 1997): 11-33. Salvador Novo. Lo marginal en el centro. México, DF: ERA, 2000.

Molloy, Sylvia. Acto de presencia. La escritura autobiográfica en Hispanoamérica. México, DF: El Colegio de México-FCE (Estudios de lingüística y literatura, XXXV), 1996.

Novo, Salvador. La estatua de sal. México, DF: CONACULTA, 1998.

Oropeza, Salvador. “La representación del yo y del tú en la poesía satírica de Salvador Novo: la influencia del albur”. Chasqui 24 (1 de marzo de 1995): 38-52.

“La mala leche barroca en la poesía de Salvador Novo”. MR 10 (1994): 71-81.

Pozuelo Yvancos, José María. “La frontera autobiográfica”. Poética de la ficción. Madrid: Síntesis, 1993. 179-225.

Ramos, Raymundo. Memorias y autobiografías de escritores mexicanos. México, DF: UNAM (Biblioteca del estudiante universitario, 85), 1967.

Roster, Peter John. La ironía como método de análisis literario. La poesía de Salvador Novo. Madrid: Gredos, 1978. 
Sedgwick, Eve Kosofsky. Epistemology of the Closet. Berkeley: U of California P, 1990.

Sheridan, Guillermo. “1921: Espíritus poseídos de divinidad”. Los Contemporáneos ayer. México, DF: FCE, 1985. 99-119.

Stanton, Anthony. "Salvador Novo y la poesía moderna”. Inventores de tradición. Ensayos sobre poesía mexicana moderna. México, DF: CELL-El Colegio de México-Fondo de Cultura Económica (Estudios de lingüística y literatura, XXXVIII), 1998. 148-76.

Villanueva, Darío. “El realismo intencional”. Semiosis 24 (enero-junio 1990): 177-99.

“Realidad y ficción: La paradoja dela autobiografía”.Escritura autobiográfica. Actas del II seminario internacional del Instituto de semiótica literaria y teatral. José Romera Castillo, ed. (Biblioteca Filológica Hispana, 14) Madrid: Visor, 1993. 15-31. 
